\title{
Research on Comparison and Evolution Mobile Customers Participate Type in Open Innovation
}

\author{
Zhen Zhang ${ }^{1}$, He Junhui ${ }^{2} *$ and Jiahua $\mathrm{Li}^{3}$ \\ ${ }^{I}$ Zhengzhou institute of aeronautical industry management \\ $*^{2}$ Department of Computer and Information Sciences, Southwest University, \\ Chongqing \\ ${ }^{3}$ Guangzhou Vocational College of Science and Technology \\ ${ }^{1}$ zhangzhen119@sina.cn, ${ }^{2}$ hejunhuicq@126.com, ${ }^{3} 908977172 @$ qq.côm
}

\begin{abstract}
Mobile Customer participation type in open innovation, enterprise innovation development path, needs to address important issues This paper proposed mobile customer sto participate typology based on three dimensions, which are the customers' autonomy in the process, the nature of the firm-customer collabordtion, and the stage of the innovation process. Then proposed mobile customers to participate in the type of open innovation framework. Through the static comparative and dynamic evolution simulation found: mobile customers tend to be open to participate in the development of new products pre innovation, the tendencye to egin to chbose the low participation of degrees of freedom, and ultimately tend to opt for a high degree of freedom to participate.
\end{abstract}

Keywords: Open innovation, nobile Customer, Participate type, Evolution simulation

\section{Introduction}

Chesbrough $2003^{\circ}$ for the first time explicitly put forward the concept of open innovation, open innoyation one of the core ideas of how to deal with the management of innovation in the presence of undertainty. In the continuous development of science and technology today, from the uncertainty of the enterprise technology, management and marketing, Thomke (2004) division of uncertainty for innovation: science and technology uncertainty, uncertainty of production processes, changes and demands uncertainty in the market, open innovation management philosophy of these factors are attributed to resource uncertainty. In order to reduce the uncertainty of resources, innovative practices adopted by companies gradually began to turn the end customer comments and suggestions for innovative activities, customer participation in open innovation activities into open mnovation theory and practice important topic. Diener and Piller (2010) in orde to "open innovation" as the theme, recalling the 244 scholars 150 papers, literature analysis found that the current network structure of open innovation researchers focus dispersion, both studies open innovation management process (Chesbrough 2003, Christensen et al 2005 ;. Gann, 2005), but also analyze the open innovation market acceptance (Mowery 2009, Linstone, 2010), as well as inter-enterprise collaborative study of open innovation (Chesbrough, Vanhaverbeke, 2006), which not only involves the management disciplines outside economics as well, Psychology and other disciplines to study the topic (von Krogh2007), but the topic of extensive research in the field scattered.

On the one hand is the business community to participate in the development of customer open innovation, on the other hand is the study of dispersion theory, the customer involved in open innovation approach which dimensions, how companies interact with mobile customers to select and form a stable relationship in open innovation state, the current lack of a theoretical framework theorists, little consensus. This study attempts to integrate customer participation in open innovation dimension, build customer 
participation in open innovation type theoretical framework, participation in open innovation type selection factors from the static and dynamic evolution of comparative study of both clients.

\section{The Type of Customer and Open Innovation}

Mobile customers to participate in open innovation in the absence of clearly stated, practitioners have been incorporated into the enterprise customer innovation activities, theorists have put forward innovative interactive customer and business can be regarded as the initial prototype. The Dahan and Hauser (2002) summarizes the approximate model framework clients in the interactive design of new products, form the basis of subsequent research. Such a framework to generate sources of customer information is based on, to interact with mobile customers and business innovation is divided into three modes: listening to customers, customer inquiries and customer collaborative innovation

The first model for the customer to listen. Customer listening mode, the use of market oriented business thinking paradigm of the new product design into the client's interests (Bartl and Ivanovic 2010). Specifically: enterprise mobile customers first collected information on similar products, combined sales of the product information and other data as inputs to analyze the situation on a market-oriented one cycle of the product. Customer listening mode mode requires sales staff feedback on a cycle of sales data, customer information, log files, or the use of customer demand research reports and other third parties (Dahan and Hauser 2002). This model features clear, simple to operate, thus extending the number of management methods: methods such as web logs, experience design and quality function deploynent, etc but this model is the existing product performance and customer requirerents linked to predict, and real customer involvement in new product design differences . The second mode is for mobile customers to ask ("ask" customers). Customer inquiries mode logically breaking the lagged effects of listening to mobile custonets, emphasizing the new product design process, ask the customer information as an input variable is introduced so that new product designs integrate into customer needs this model reflects the customer-oriented thinking paradigm . Customer inquiries mode specific methods are: conduct customer surveys in new product design, in-depth interviews or group seminars and other forms of qualitative implementation (Griffin and Hauser 1993), but because of the qualitative analysis concluded dispersed eustomer inquiries often very difficult to form an effective customer information gathering so follow-up studies on the specific method has been improved, companies tend to be made in advance of new product design innovative designs swarm alternative, while organizing clients asked to accept more mobile customers for feedback of (Dahan-and Hauser 2002). The greatest feature of this type of model is the new products and new mobile customers logically organic link, thus avoiding the prior period data for future predictive bias. The third mode of business and customer collaborative innovation ("build" with customers). Collaborative innovation model trying to solve isolated features and enterprise customers, trying to break the boundaries of enterprise mobile customers and allow mobile customers to actively and effectively, and participate in new product innovation synchronous design and development process. This pattern is typical of mobile customers- business - open innovation interaction with customer's integrated model. Therefore, this mode is a built on the understanding of 'customercentric'actively integrate innovative customer engagement models (von 2002), is a client involved in a high degree of innovation activity reflected.

\section{An Open Innovation Dimension of Customer Engagement}

Mobile customers can promote new product innovation activities of enterprises in different modes and strength. The new product innovation practice tells us: corporate clients and collaborative innovation of new products, is a diverse phenomenon, characterized by the need to get the dimensions from the customer's interaction with the 
business process. Based on the results of previous studies of open innovation, draws Diener and Piller (2010) open innovation characteristics, we propose three dimensions of customer participation in open innovation characteristics: Mobile customers to participate in open innovation stage : that point in time mobile customers into open innovation. This feature is mainly portrayed the customer at which stage of new product innovation, open innovation fit into. If the existence of a new product concept design, pre- design phase of development, or to try a new product, new products such as the late stages of testing in practice. We define it as the customer's participation in open innovation front and rear two dimensions. Degree of synergy mobile customers to participate in open innovation: refers to an open innovation basic relationship structure, how companies deal with innovation set with the customer, that a business synergistic innovative customer mathematical much, and the tightness at the same time. We define it as a high dégree of synergy for our mobile customers to participate in open innovation and low two dimensions (Diener, K. and Piller, F. 2010).Degree of freedom of mobile customers to participate in open innovation: open innovation refers to the task of enterprises, assigned to the nature of the client, giving mobile customers the freedom to in ox xate-in the space. Open innovation tasks those businesses whether it is narrow and scheduled tasks or more liberal loose, creative tasks (Franke, N. et al. 2010). We define it as a high degree of freedom for mobile customers to participate in open innoyation with a low degree of freedom in two dimensions.

\section{The Type of Mobile Customersto Participate in Open Innovation Dynamic Evolution Simulation}

The simulation model can examine specific to a particular level of uncertainty, with the change of time how to reflect the impact of the target. As the simulation using process models to reproduce the true nature of things in the system development in the economic system, the use of natural phenomena and other areas more widely.Simulation of current common tools SFL's Swarm, Starlogo, Northwestern University Netlogo, University of Chicago, MIT, etc Repast. Repast Swarm are the traditional organization and systems oriented in terms of modeling fime and maintenance costs are relatively high, while not fully reflect the mobile customers to participate in open innovation approach the subject of dynamic and collaborative enterprise customers. Modeling time and maintenance costs Netlogo simulation is relatively low for mobile customers to participate in open innovation approach characteristic of research , the study of complex systems modeling draw ideas, with Netlogo simulation platform for mobile customers to participate in the evolution of open innovation approach will be modeling and Simulation .

The basic assumption NetLogo model space is divided into a grid, the grid formed the basic form of the simulation system. Multiple mobile Netlogo distributed in two dimensions, each Netlogo can be updated with the changes in the environment. NetLogo modeldefines the main ideas of Agent -based modeling, through the abstract as the basic unit of the Agent system, along with some intelligence, and then set a specific way interaction between multiple Agents, get the system model. Agent runs on actors with custom programming language, Windows, Linux and other mainstream platforms. Another NetLogo is an interpreted language, it built a turtle graphics system, by sending commands to the turtles, the user can run the process observed visually. Therefore, we can use a visual representation of the simulation results shown in Figure simulation results.

\subsection{Two Types of Mobile Customers to Participate in the Evolution of Open Innovation Simulation Design}

Innovation is the type of mobile customers to participate in the process of evolution of open abstracted, our hypothesis is as follows: 
Hypothesis 1: Assume that over time, mobile customers in the enterprise open innovation have reached the limit of three ways;

Hypothesis 2: Each model has a willingness to participate in a customer open innovation, customer i 's participation in decision-making behavior of open innovation consists of three parts: the open innovation stage, the degree of customer engagement and customer participation in collaborative degree of freedom .

Hypothesis 3: Individual mobile customers three ways to open innovation initial values are different and affected by other customers. After each individual customer to move to a place that will be open to innovative ways to spread around the neighborhood customers, neighbors classic definition of Moore neighborhood definition. Depending on individual preferences, we define Agent different attributes, and then the following model rule interactions. In accordance with the definition of the utility function, when the actual utility mobile customers to participate in open innovation better than expected utility Agent threshold, utility y is 1 , and 0 otherwise ; accepted when the surrounding neighborhood open innovation approach than the social impact of Agent hreshord, social impact of utility $\mathrm{x}$ is 1 , and 0 otherwise ; according to the totar utility function , calculated for each Agent 's total utility U, U is greater than the total ytility when the utility agent threshold Umin, Agent accepts open/mnovation approach/, or do not accept it.

According to the model assumptions, the simulation program is divided into two parts: the initialization parameters and attributes defined Agent actions. Initialization parameters defined attributes mobile customers. Initialopen innovation in the enterprise customer number is 100, randomly distributed on the grid No matter how open innovation approach, is greater than the threshold utility mobile customers, mobile customers are unconditionally accept open innovation approach, mobile customers Agent must be open to innovative ways to spread around the neighborhood mobile customers Agent. Agent according to neighbors mobile customers choose whether to accept the decision function of open innovation appreach, recipient of the open and innovative ways to further inform their neighbors mobile cystomers Agent. Among them, the number of potential mobile customersN2 on the market equillibrium coefficient $\beta$ and social impact threshold $\mathrm{h}$ artificially regulated by the slicer. mobile customers are randomly distributed on the grid. Balance coefficient $\beta$ in the range between 0 and 1 , thanks to Moore neighborhood definition, the maximum number of neighbors Agent 8, the impact of the threshold $\mathrm{h}$ ranges between 0 to 8.

Definition of agent actions are as follows: Client Agent to participate in the open innovation movement consists of three components: open innovation stage, the degree of customer engagement and customer participation in collaborative degree of freedom. Research based on evolutionary game model set of mobile customers to participate in the evolution of Agent rules are as follows: Vi Agent represents clients involved in open innovation stage, Wi Agent represents clients in the enterprise collaborative open innoyation extent size. Ii said mobile customers are free to participate Agent impact size. First calculate the customer Agent utility function utility exceeds acceptable threshold, if it exceeds the state becomes the recipient of an action, if not more than continue to maintain the original state. Have been recipients of the action in the next simulation run spread to surrounding mobile customers Agent, each one will be moved to the open innovation approach to information to inform surrounding Agent; Agent on the grid to move rules are as follows: first the individual right, then forward progress before the number between 0 and 10 randomly selected a value, then turn left. After the end of the movement, Agent computing utility functions again and decides whether to accept the way, followed by cycle. In order to examine the evolution of open innovation Agent clients in three ways, in particular examine whether the formation of the stability of the state, we do not have artificial termination of command. 


\section{Types of Mobile Customers to Participate in the Evolution of Open Innovation Analysis of Simulation Results}

Mobile customers participating companies to examine three types of open innovation in the dynamic evolution of the existence of significant differences, we designed four simulation program and analysis of results.

\subsection{Option One: Impact Mobile Customers to Participate in Open Innovation Stage of Open Innovation}

In order to verify the impact of Vi represents the client agent involved in open innovation stage in the other parameters remain unchanged, consider the customer agent to participate in open innovation stage $[0,1]$ distribution, changes in customer agent to participate in open innovation stage, testing with different customer agent involved in the timing of open innovation, customer engagement behavior is significantly gtranged.

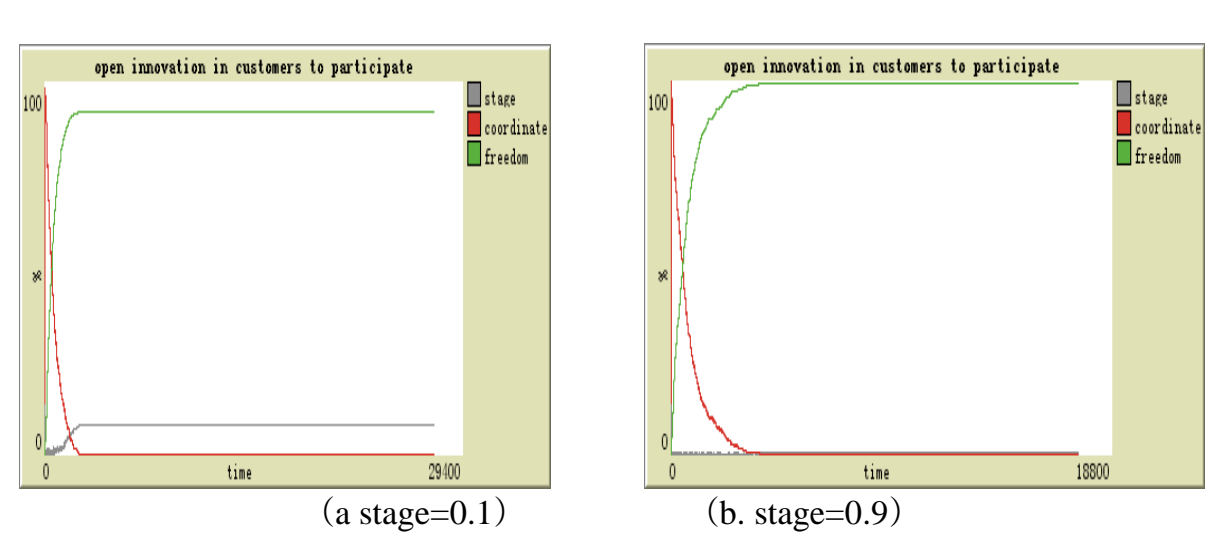

\section{Figure 1. Comparison Simulation Results of Customer Engagement Stage}

Figure 1a client agent involved in the value of open innovation phase 0.1, Figure $4 \mathrm{~b}$ value of 0.9 , there are two significant differences between the results of evolution: first, in the steady state, the customer the opportunity to participate in open innovation there is a dynamic evolution. If the customer choose the rear end of the beginning involved, the next stage involved the evolution of the earlier described earlier stage of the overall customer likes to participate; Secondly, the degree of freedom significantly impact customer involvement, customer involvement in the open front of innovation, the latter tends to stabilize the freedom to choose to participate in the open innovation approach about $92 \%$ while the back end of open innovation in customer participation, tend to choose to participate freely in the open innovation approach tends to be stable after $100 \%$. This shows that mobile customers participate in open innovation front, some mobile customers will remain collaborative innovation and corporate relations.

\subsection{Option Two: Mobile Customers Participating in the Extent of the Impact of Open Innovation Collaboration}

We set the other parameters remain unchanged, the client agent to change the degree of participation in open innovation collaboration, test agent with the customer to participate in different levels of collaborative open innovation, customer whether the conduct involved in significant changes will occur. 

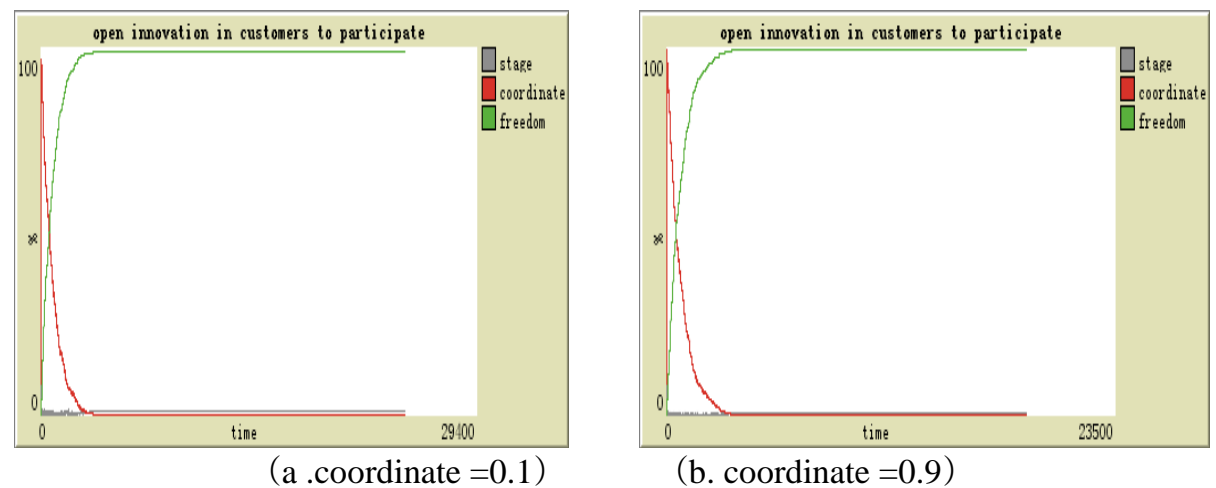

(b. coordinate $=0.9$ )

Figure 2. Comparison Simulation Results of Customer Coordinate

Figure 2a client agent involved in the value of open innovation collaborat le degree 0.1 , Figure $b$ value of 0.9 , there is little nuances evolytionary result: lower initial collaborative customer degree ( 3 a Figure), the client time to participate in the next stage of consideration in decision-making delayed participation. ${ }^{\mathrm{Can}}$ be understood as the beginning of providing a very high degree of freedom of the open innovation platform, mobile customers did not start to adapt, it mayeven be excluded, and behavioral characteristics of rejection is delayed participation stage.

\subsection{Option Three: Mobile Customers Participating in the Degree of Freedom of the Impact of Open Innovation to Open-Finovation}

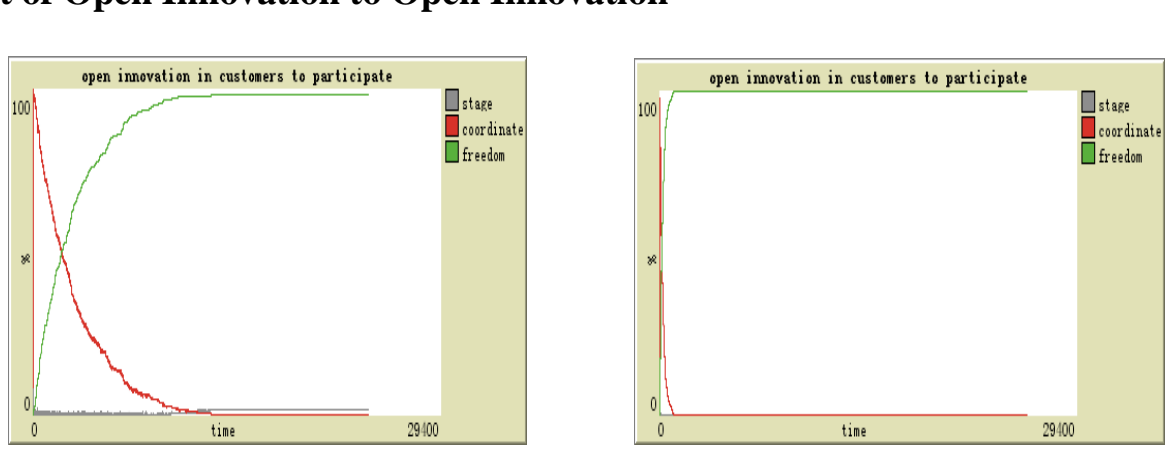

(a. freedom=0.1)

(b. freedom=0.9)

Figure 3. Comparison Simulation Results of Customer Freedom

Figure 3 a client agent involved in the degree of freedom of the open innovation value 0.1 , Figure $6 \mathrm{~b}$ value of 0.9 , there are two distinct evolutionary result: First mobile customers to participate in the open innovation degree of freedom of the evolution rate, the initial level of customer participation in open innovation freedom low, and gradually into the high degree of freedom after experiencing the typical type of learning curve, ultimately tend to choose high degree of freedom of the open innovation approach mobile customers to participate in the initial high degree of freedom of open innovation, then quickly select a high degree of freedom of the open innovation approach, visible a high degree of freedom of the open innovation approach is the ultimate tendency of mobile customers to choose; secondly the degree of participation in open innovation collaborative enterprise evolution there are significant differences as well. Mobile customers began to participate in the low degree of freedom of the open innovation mobile customers, after more tendency to high levels of innovation and collaborative approach will gradually evolved and eventually be replaced by a synergistic manner open innovation approach high degree of freedom, and the initial level of customer participation in open innovation freedom high, if there is corporate incentive mobile customers to choose a synergistic 
manner, even if the customer has to try, but it would quickly return to the way a high degree of freedom, which illustrate the high degree of freedom for mobile customers innovative ways to be more preferences.

\subsection{Option 4: Number of Enterprise Mobile Customers to Participate in the Impact of Open Innovation}

In order to verify the customer under the impact of the number of companies involved in open innovation, we set other parameters unchanged, namely to change the number of mobile customers Agent, testing increased participation in open innovation with enterprise mobile customers, whether the customer engagement behavior will change significantly.

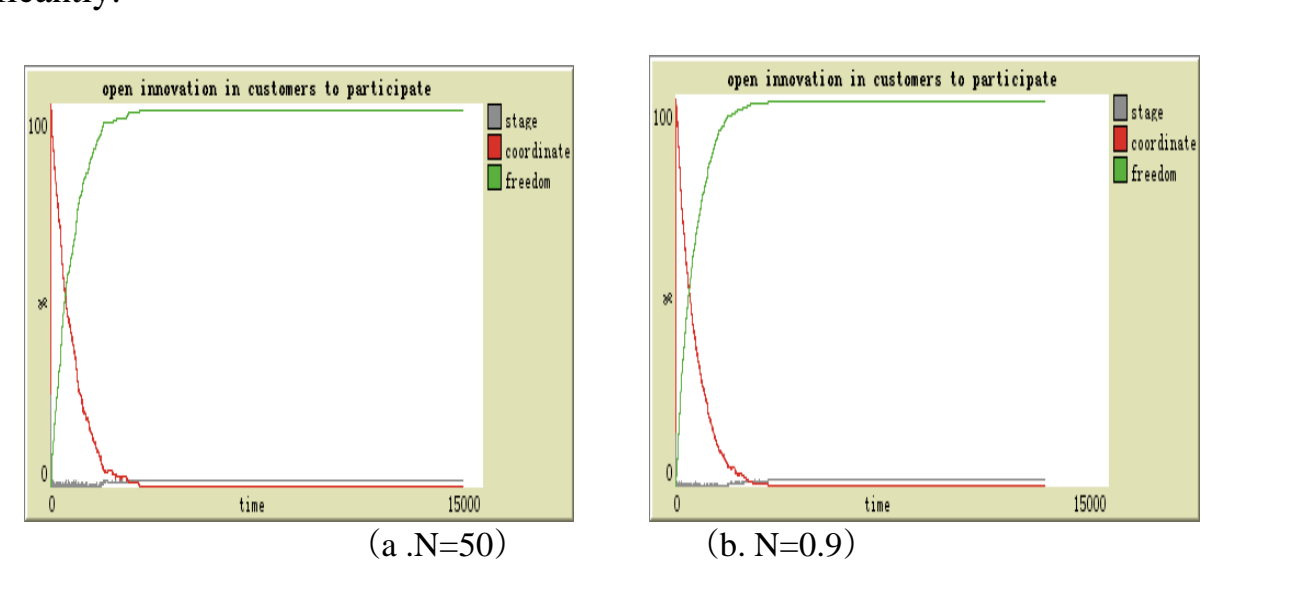

Figure 4. Mobile Customers in the Comparison of Simulation

There are 50 mobile custorners in Figure $4 \mathrm{a}$ and $4 \mathrm{~b}$ agent has 500 clients agent, there is no significant difference between the results of evolution. At steady state, the way mobile customers choose to participate in open innovation, there is no significant relationship between the numbers' of firms with clients open innovation platform, the smaller the impact of open innovation platform for social network size of the individual. Meanwhile, the equilibrium state, mob(ie) customers will tend to participate in collaborative degree, but then the customer the freedom to participate in awareness and freedom to participate absolute dominance on addition, in the case of changes in the number of customers, clients participate in open innovation platforms were earlier timing.

\section{Conclusions}

Through open innovation characterize customer engagement phase, collaborative dimension of the extent and degree of freedom of the three proposed mobile customers to participate in the type of open innovation framework. Static analysis by comparing the results: Collaborative extent and the degree of freedom of mobile customers to participate in open innovation have a significant impact, innovative task uncertainty, the stronger, the lower the extent and degree of freedom collaborative customer participation; through dynamic evolution simulation results: Mobile customers willing to participate in new product design pre- open innovation, mobile customers choosing a low degree of freedom of participation, but ultimately tend to a high degree of freedom of choice of participation.

\section{Conclusions and Implications}

According to the static and dynamic simulation analysis comparing, we propose management following meanings: 
First, companies build an open collaborative innovation platform may consider innovative ways to start, from the "lead users" as the focal point (von Hipper 2002) [14]. Simulation results show that collaborative innovation approach is consistent with preferred mobile customers and business contacts, subsequent evolution of the customer before choosing a high degree of freedom innovative ways. Visible collaborative innovation platform provides mobile customers can either attract mobile customers to participate, but also to guide mobile customers the freedom to innovate. Enterprises seeking advance into collaborative innovation platform " lead users " very important " lead users " Enterprise mobile customers first by the community, such as new product forums, online communities, such as the identification of those users are active in the community and mobile customers, and with influential to communicate, and guide them to discuss issues related to the new product, if necessary, and the " lead users " VIP status granted direct contact ; secondly can enhance the " lead users" perceived value by "Yead users " to try new products, new product ideas show etc. thus the "lead users " continue to play a role .

Second, companies can use social media marketing optimization open innovation activities to improve the customer's learning curve. Comparison of static and dynamic simulation results show that: Mobile customers participating in open innovation platform obvious learning curve. But improving customer learning curve is not a traditional employee training mode, you can make full use of the customer and business contacts in social media, social media marketing, such as the use of social networks, online communities, blog, microblogging letter to mobile customers through innovation to provide conscious, dispersion, fragmentation help

Also open innovation business activity data ean be introduced to increase the degree of freedom of mobile customers to paticipate in the marketing of open innovation. No matter how the simulation conditons change, consistent with the simulation results show that: The tendencies of mobile customers are willing to freely open innovation activities in a stable condition. Mobile customers freedom of open innovation for enterprises facing difficulties unstructured data, traditional customer relationship management CRM customer innovation is difficult to promote the degree of freedom, we can introduce the idea of marketing data. First, change the concept of data collection, with the collection of network characteyistics suct as critical data access rate, traffic, conversion rate and other pages, the customer's behayior becomes unstructured structured data; secondly consider customer interaction in social networks, with the general trend of social network analysis platform for open innovation.

\section{Prospectsfor Future Research}

The first is the mechanism of open innovation category for enterprise mobile customers to participate in how to create sustainable competitive advantage. Now open innovation behavior of enterprises participating mobile customers have gradually rise, competition for business mobile customers from the new product development phase has already begun. With clients in many sectors of open innovation, the future customer base will gradually become a scarce resource, increase the cost of innovation enterprises, and enterprises should be the degree of customer participation in open innovation collaboration, degrees of freedom and participation stage into the business to create a sustainable competitive advantage in the past. This requires further study its mechanism of action, combined with case studies and empirical research on specific strategies to guide enterprises.

Followed by a comparative study of mobile customers to participate in open innovation integration. For the vast majority of industry enterprises, the number of mobile customers is even more massive, many industries are using statistical methods to predict customer demand, but mobile customers need to differentiate actual existence is an important issue, 
as mobile customers participate in the open innovation involves customer-oriented and market -oriented, and larger differences in class, although there are other tools such as mass customization can solve the different needs of individual mobile customers, but there is no uniform standard solutions for mobile customers to participate in open innovation integrated overall framework and classification of the current need to be explored .

Another customer information to assess the research enterprise mobile customers involved in open innovation. Mobile customers participating in open innovation information provided is fragmented, but important, and how companies put their resources effectively combine customer information, and ultimately determine the correct information for decision support company. The current study has methodological research from information management, decision support systems perspective, but also innovation in information management research firm, the theory and methodology of how these future mobile customers to participate in the open innovation combine is animpprtant part of future research.

\section{Acknowledgements}

Supported by the Fundamental Research Funds for the Central Utiversities (XDJK2013C012); Chongqing education science the 12th five-year plan (2012- GX - 022) of the project.

\section{References}

[1] H. W. Chesbrough, "Open Innovation. The New Imperative for Creating and Profiting from Technology" Boston, MA [J]", Harvard Business S hool Press, (2003), pp. 43-62.

[2] S. Thomke and E. von Hippel, 'customers as innovators: a new way to create value [J]", Harvard Business Review, vol. 80, no. 4,(2002), pp. 74-81.

[3] K. Diener and F. Piller, "The Market for OpenNinnovation [J]", Raleigh, NC: Lulu (2010), pp. 11-13.

[4] J. F. Christensen, M. H. Olesen and J. S. K/aer, The industrial dynamics of open innovation-evidence from the transformation of consumer electronics [J]", Research Policy, vol. 34, (2005), pp. 1533-1549.

[5] D. M. Gann, "Book review: open innovation: the new imperative for creating and profiting from technology [J]", Research Policy, 134 , (2005), pp. 122-123.

[6] D. C. Mowery Plus ca change: infustrial R\&D in the "third industrial revolution"'. [J]", Industrial and Corporate Change, (2009), vol. 18, pp. 1-50.

[7] H. A. Linstone, "Commen on 'Is open innovation a field of study or a communication barrier to theory development? [J]", Technoyation, (2010), pp. 630-56.

[8] H. Chesbrough, W. Vannaverbeke and J. West, "Open innovation: Researching a new paradigm [M]", Oxford: Oxford University Press, vol. 8, (2006), pp. 89-90.

[9] G. von Krogh and S. Spaeth, "The open source software phenomenon: characteristics that promote research [JJ', The Journal of Strategic Information Systems, vol. 16, no. 3, (2007), pp. 236-253.

[10] E. Dahan and J. R. Hauser, "The virtual customer [J]", Journal of Product Innovation Management, vol. 19, no. 5, (2002), pp. 332-353.

[11] M Bartl and I. Ivanovic, "Netnography - Finding the right balance between automated and manual tesearch", In: Web-Monitoring, [J]”, UVK Publishing, Konstanz, (2010), pp. 157-174.

[12] A. Griffin and J. R. Hauser, "The voice of the customer [J]", Marketing Science, vol. 12, no. 1, (1993), pp. 20-27.

[13] E. Dahan and J. R. Hauser, "The virtual customer [J]", Journal of Product Innovation Management, vol. 19, no. 5, (2002), pp. 332-353.

[14] E. von Hippel and R. Katz, "Shifting innovation to users via toolkits [J]", Management Science, vol. 48, no. 7, (2002), pp. 821-833.

[15] F. Piller, C. Ihl and A. Vossen, "Aachen A typology of customer co-creation in the innovation process[J]", working papers, vol. 6, (2010), pp. 23-25.

[16] M. S. O'Hern and A. Rindfleisch, "Customer co-creation: a typology and research agenda [J]", Review of Marketing Research, vol. 6, (2009), pp. 84-106.

[17] J. Füller, G. Jawecki and H. Mühlbacher, "Innovation creation by online basketball communities [J]", Journal of Business Research, vol. 60, no. 1, (2006), pp. 60-71.

[18] J. Howe, "Crowd sourcing: Why the Power of the Crowd Is Driving the Future of Business [J]", New York, NY: Crown, vol. 6, (2008), pp. 53-57. 


\section{Authors}

Zhen Zhang, male, Zhengzhou institute of aeronautical industry management, zhangzhen119@sina.cn

He Junhui, corresponding author

He Junhui (1981- ), male, lecturer of chongqing, southwest university lecturer, management doctoral, majoring in electronic commerce.

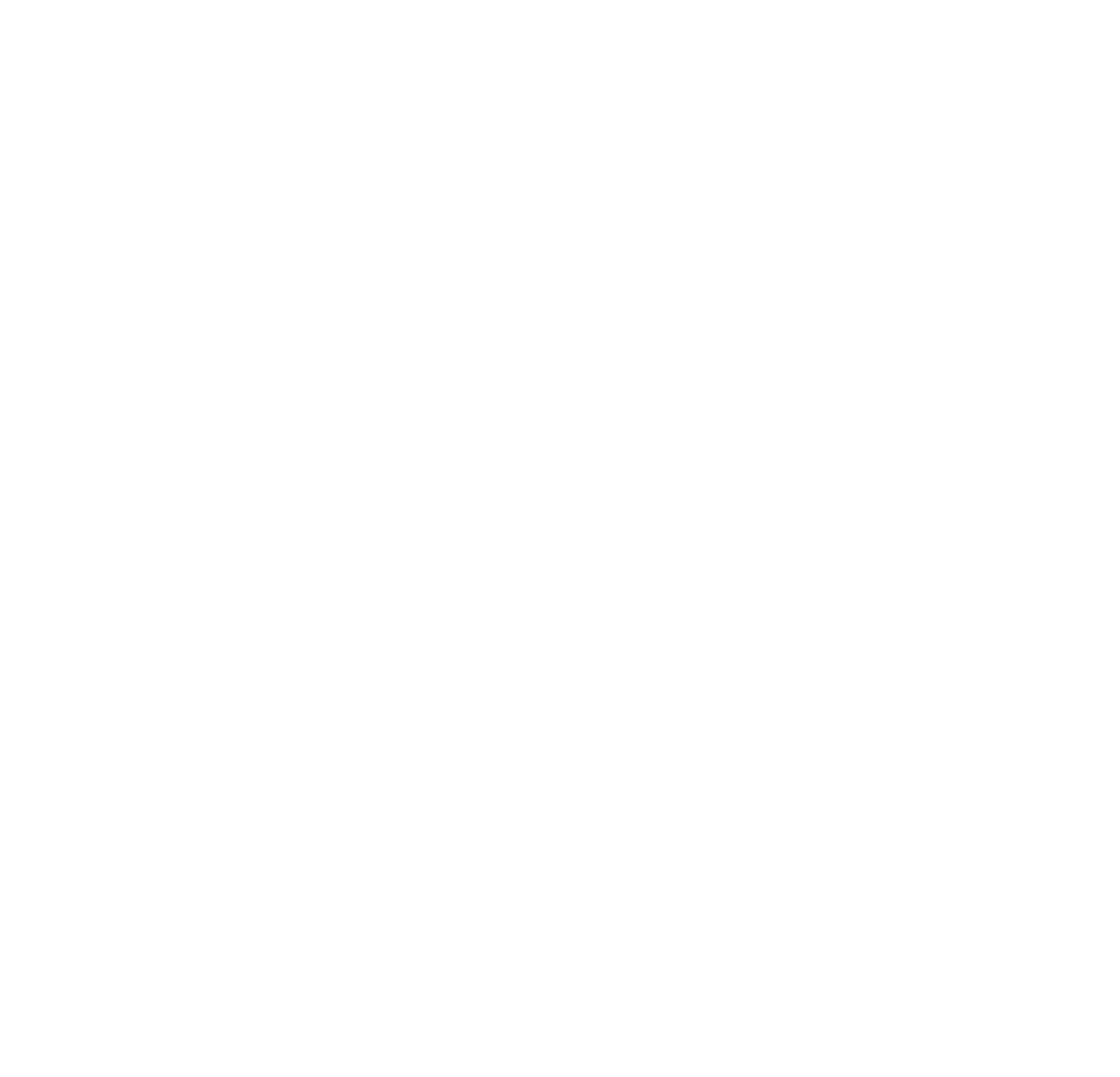

